PONTIFÍCIA UNIVERSIDADE CATÓLICA DO RIO DE JANEIRO

\title{
A Crise Previdenciária Brasileira: Paralelos e Reformas
}

Tiago Fraga

TRABALHO DE CONCLUSÃO DE CURSO

Centro de CIÊnCIAS sociais - CCS

DePARTAMENTO de AdMINISTRAÇÃO

Graduação em Administração de Empresas 
Tiago Fraga

\section{A Crise Previdenciária Brasileira: Paralelos e Reformas}

\section{Trabalho de Conclusão de Curso}

Trabalho de Conclusão de Curso apresentada ao programa de graduação em Administração da PUC-Rio como requisito parcial para a obtenção do título de bacharel em administração de empresas.

Orientadora: Graziela Fortunato

Rio de Janeiro

Junho de 2019. 
"Se o remédio é amargo, mas o paciente precisa dele para sobreviver, devemos suspender 0 remédio?"

(Margaret Thatcher) 


\section{AGRADECIMENTO}

Agradeço imensamente à minha família por apoiar minhas decisões e me ensinar os valores que carrego comigo. Aos meus amigos, por me incentivarem a ser sempre melhor. Agradeço a todos os professores que tive em minha vida.

Agradeço especialmente à minha mãe e à minha avó, por me fornecerem condições de completar esse curso e acreditarem nos meus objetivos. 


\section{RESUMO}

A constituição brasileira de 1988 criou a previdência social em atividade no Brasil em 2019. Um marco enorme, criado a partir das demandas da época e em cima das características da época. O país passou por diversas mudanças nesses 31 anos e nossa demografia não é a mesma de antes. $O$ trabalho em questão levanta em que termos a previdência social está com a realidade brasileira, a compara com a de outros países pelo mundo e analisa a proposta do governo Bolsonaro diante disso.

Palavras-chave: Previdência social. Reforma da previdência. Generosidade paramétrica. Governo Bolsonaro. Demografia brasileira. 


\begin{abstract}
The Brazilian constitution from 1988 created the social security system seen in 2019. An enormous achievement, generated from the demands of that time based on the characteristics of that time. The country went through a lot of changes in these 31 years and our demography is not the same as it used to be. This thesis inquires on the state of the social security in relation with the Brazilian reality and compares it with those of other countries around the world to analyze the new reform proposition from Bolsonaro's government.
\end{abstract}

Keywords: Social security; Security reform; Parametric generosity; Bolsonaro's government; Brazilian demography 


\section{SUMÁRIO}

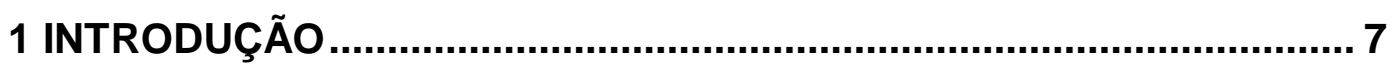

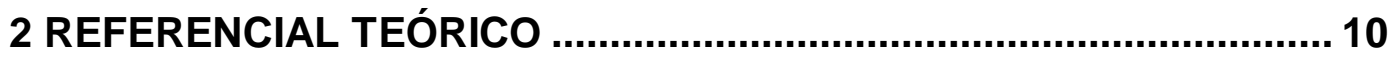

2.1. As mudanças demográficas no Brasil ......................................... 10

2.2. O regime previdenciário de capitalização...................................... 12

2.3. A previdência social em outros países .......................................... 14

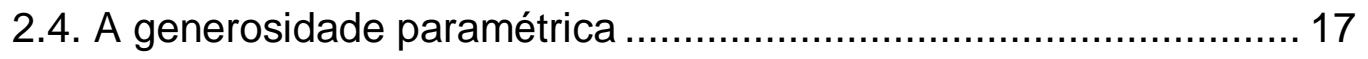

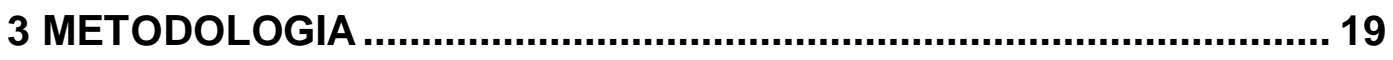

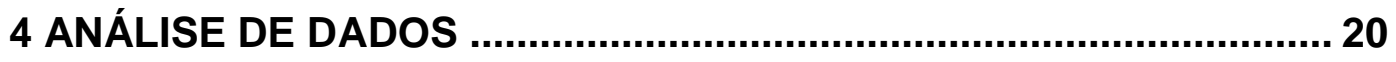

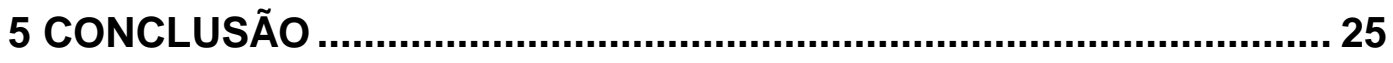

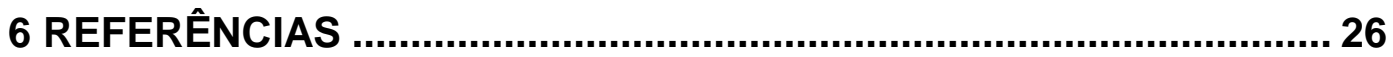




\section{Introdução}

A previdência social brasileira deu seus primeiros passos na década de 20 e passou por diversas transformações até chegar no molde de 2019, iniciado pela constituição de 1988.

Uma de suas principais características é o regime de repartição, isto é, os contribuintes atuais sustentam os aposentados atuais. Possui três formas de admissão: Por idade (65 para homens e 60 para mulheres), por tempo de contribuição (35 para homens e 30 para mulheres), invalidez (sem restrição de tempo, o indivíduo que provar estar incapaz de exercer qualquer atividade laborativa pode se aposentar por esse meio). Existem ainda exceções especiais nas regras ao se tratar de povos indígenas, rurais e trabalhadores expostos a agentes nocivos. Funcionários públicos da esfera estadual e municipal também possuem regras diferenciadas.

Nos últimos 30 anos, os governos de Collor, FHC, Lula e Dilma fizeram alterações nas regras da previdência a fim de adaptá-las ao dinamismo econômico e reduzir as vantagens do setor público em comparação ao privado (Giambiagi, 2019).

O assunto da previdência social tornou-se um dos principais temas de discussão política nos últimos anos no Brasil. Isso se deve aos recorrentes resultados de déficit primário (desde 2014) que apontam um desequilíbrio fiscal no país registrado em $R \$ 120,26$ bilhões em 2018. Esse cenário se manifestou devido ao rápido aumento de despesas em \% do PIB (chegando a 19,5\% em 2017), que por sua vez ocorreu devido às mudanças demográficas brasileiras que sobrecarregam nosso sistema previdenciário e pela desaceleração da economia nacional, acumulando uma recessão de 4,8\% do PIB de 2015 a 2018.

Por essas razões, o Estado brasileiro iniciou fortes movimentos para uma maior mudança nas regras da previdência. Desde as primeiras declarações da presidente Dilma em 2016, até a derrotada proposta de reforma do presidente Temer e ministro Meirelles em 2018 e a nova proposta do presidente Bolsonaro e ministro Guedes de 2019. As propostas apresentadas por Temer e Bolsonaro são semelhantes e 
possuem como principal ponto a adoção de uma idade mínima obrigatória de aposentadoria (que não seja ignorada por tempo de contribuição). A proposta de Bolsonaro se distinguiu por ser mais dura com 0 funcionalismo público e adotar algumas diferenças de contribuição por renda, além do mesmo declarar ser favorável a uma futura adoção do sistema de capitalização.

Dessa forma, torna-se necessário analisarmos o tema para contribuir com a qualidade de discussão do tópico. Detectar as alternativas disponíveis e apontar aquelas que se mostram mais viáveis e adequadas à situação brasileira.

Portanto, diante dos problemas apresentados, o objetivo desse trabalho é oferecer dados, argumentos e informação acerca da previdência social brasileira e da reforma previdenciária prevista para 2019 a fim de saber se o Brasil tem a capacidade de sair da crise fiscal. $O$ presente trabalho mostrará em que situação fiscal o Brasil se encontra e os parâmetros de admissão e benefícios da aposentadoria praticados aqui e em outros países. Para isso será desenvolvido um estudo dos tipos de previdência conhecidos e das práticas de outras nações diante do mesmo problema.

O trabalho em questão pretende dar ênfase à situação demográfica e econômica do Brasil em 2019, assim como à proposta de reforma desenvolvida pelo governo Bolsonaro, considerando o tópico como de enorme importância para a vida de todos os brasileiros por se tratar de mudanças drásticas na idade de aposentadoria.

$O$ texto busca satisfazer o interesse de todos aqueles inseridos em discussões sócio-políticas e econômicas do Brasil, assim como estudantes e acadêmicos da área. A ideia aqui presente é contribuir para o debate demonstrando a abordagem internacional frente a reformas previdenciárias e às condições atuais do Brasil.

A contribuição desse trabalho será fornecer uma análise atual do problema previdenciário, feita no calor das discussões do tema e comparando as ideias propostas em 2019 pelo governo brasileiro com a teoria levantada e a realidade ao redor do mundo. 
A delimitação deste trabalho é a abordagem do atual cenário econômico brasileiro, o histórico demográfico (1980 em diante) e as propostas previdenciárias em discussão em 2019.

Este trabalho está organizado de maneira a primeiramente apresentar ao leitor o histórico político recente no que tange à previdência social, em seguida o histórico e revisão das teorias dentro do Referencial Teórico. O terceiro capítulo apresenta a metodologia adotada na pesquisa: coleta de dados, análise descritiva e comparação com o objeto de estudo. O quarto capítulo traz a análise dos resultados e ao fim a conclusão e sugestões para pesquisas futuras. 


\section{Referencial Teórico}

\subsection{As mudanças demográficas do Brasil}

Passaram-se 31 anos desde a constituição de 1988. A redemocratização da nação brasileira trouxe consigo diversas reformas, entre elas, o formato de previdência social que possuímos em 2019. Nessas três décadas, a população brasileira mudou bastante. A expectativa de vida que era de 62,5 anos em 1980 chegou a 76,3 anos em 2018 (IBGE, 2018). Observa-se na Figura 1 uma comparação entre a \% da população de idosos e jovens de 1980 até 2018 e uma estimativa do IBGE para 2048, assim como a expectativa de vida do brasileiro sob os mesmos parâmetros.

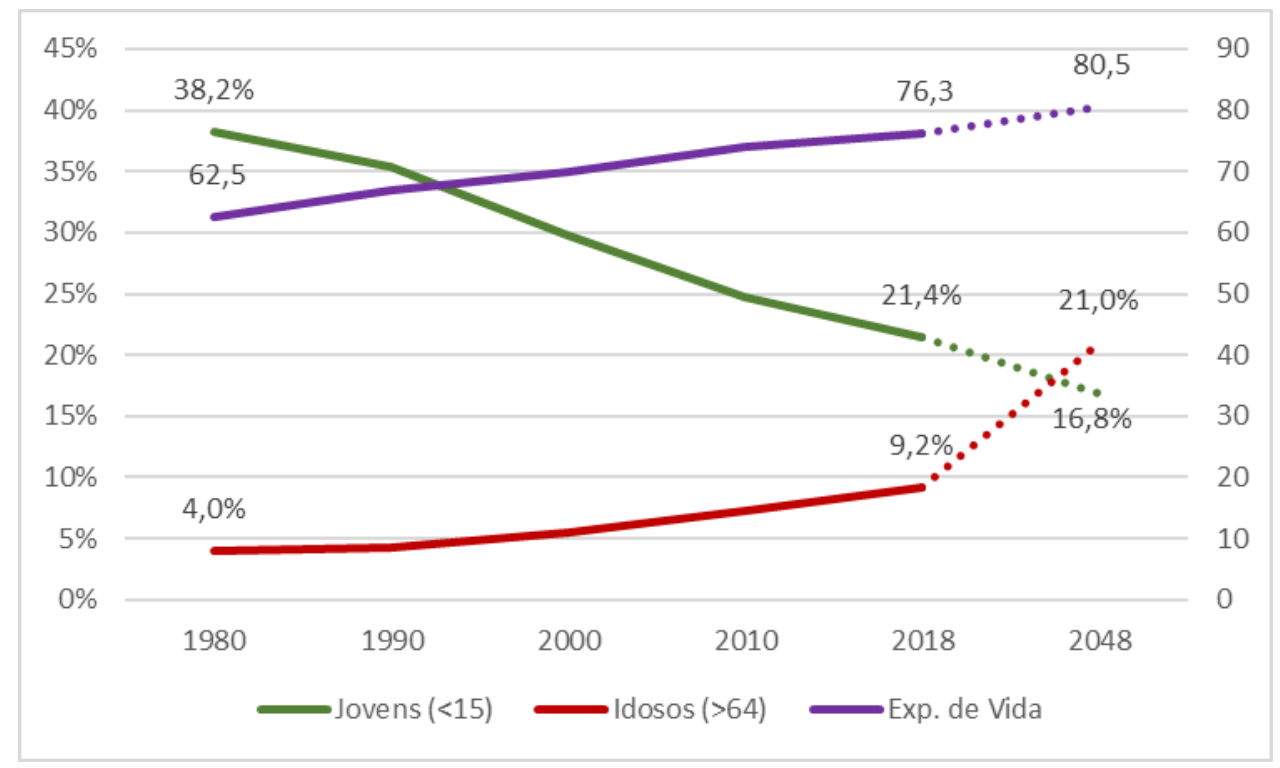

Figura 1: Crescimento da expectativa de vida do brasileiro

Fonte: IBGE

Ao analisar o Índice de Envelhecimento (quantidade de pessoas com mais de 60 anos de idade para cada 100 pessoas menores de 15 anos), percebe-se um grande aumento: de 15,9\% em 1980 para 44,8\% em 2010. O Brasil não só tem cada vez mais idosos (>64 anos), mas também menos crianças e adolescentes (<15 anos). Enquanto o primeiro grupo aumentou de 4\% em 1980 para 9,2\% em 2018, o segundo diminuiu de 38,2\% em 1980 para 21,4\% em 2018. A tendência é que a participação de idosos na população brasileira seja de 17,4\% em 2040 
(Miranda et al., 2016). Esses dados refletem bem a diminuição da taxa média de fecundidade, registrada em 4,1 em 1980 e 1,8 em 2018.

Credita-se a queda de natalidade na crescente utilização de métodos contraceptivos e na disseminação e investimento em educação sexual, enquanto a redução da taxa de mortalidade ao avanço da medicina e crescente investimento em saúde (NASCIMENTO, 2015). Esses fatores somados resultam no aumento de expectativa de vida da população brasileira.

Observa-se a transformação da demografia brasileira através da pirâmide etária. Em 1980 o Brasil tinha uma população majoritariamente jovem, enquanto que em 2015 nossa pirâmide começa a se aproximar da forma europeia, onde a faixa de recém-nascidos e crianças diminui drasticamente e a população mais velha aumenta.

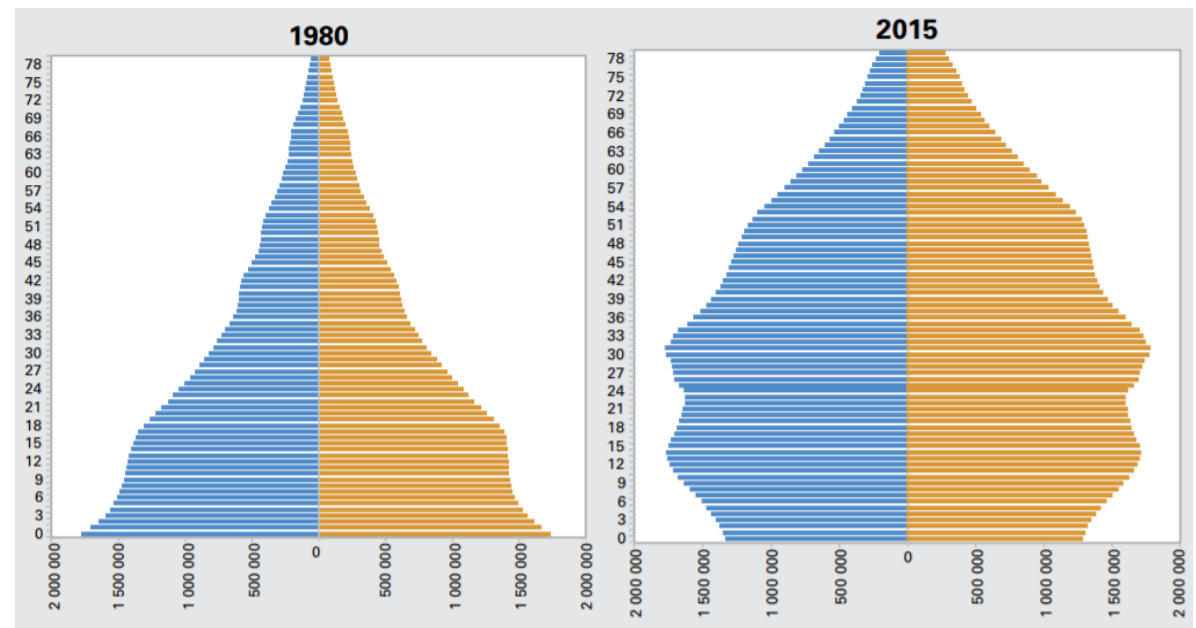

Figura 2: Pirâmide demográfica brasileira Fonte: IBGE

Nascimento (2015) afirma:

O aumento da expectativa de vida causou e vem causando uma série de reformas no sistema previdenciário brasileiro. De um lado a crise gerencial para manter os valores dos financiamentos em paridade com a quantidade de benefícios que são concedidos, por outro lado quanto mais velha e mais longeva se torna a sociedade, é necessária rever toda a forma de concessão de benefícios.

Essas mudanças não ocorreram apenas no Brasil. Observa-se a mesma tendência em nossos vizinhos latinos: Segundo o Banco Mundial, 
a expectativa de vida em 1980 na Argentina, Chile e Uruguai era de 69,5 anos, 69,1 anos e 70,3 anos, respectivamente. Em 2015, esses números saltaram para 76,4 anos, 79,3 anos e 77,3 anos, respectivamente.

Considerado um dos mais importantes dados estatísticos para o assunto da reforma da previdência, a Expectativa de Sobrevida precisa ser destacada nessa discussão. Esse cálculo exclui a mortalidade infantil, assim como desconsidera mortes de jovens (maiores sujeitos a criminalidade), revelando uma expectativa de quantos anos a pessoa ainda terá de vida em uma faixa etária específica. No Brasil, uma pessoa de 30 anos tem expectativa de sobrevida de mais 48,5 anos, ou seja, até os 78,5. Aos 60 anos de idade, já próximo da aposentadoria, a expectativa de sobrevida é de mais 22,4 anos ou até os 82,4 anos. Analisando através dessa estatística, pode-se concluir que se uma pessoa se aposenta aos 65 anos de idade, a expectativa é que ela viva até os 83,7 (expectativa de sobrevida aos 65) e não até os 76 (expectativa de vida ao nascer). Em 1985, três anos antes da constituição da nossa previdência social, a expectativa de sobrevida nessa mesma idade era de 77 anos.

\subsection{O regime previdenciário de capitalização}

Os primeiros estudos acerca do tópico iniciaram na década de 70 quando Munnell (1974) e Feldstein (1974) descreveram que ao garantir um nível mínimo de recursos na aposentadoria, reduzir-se-ia o esforço do indivíduo para acumular recursos durante a vida, reduzindo o nível de poupança agregada. Ambos os estudos foram importantes para motivar 0 desenvolvimento dos regimes de capitalização. Observa-se que nessa época os maiores fatores motivacionais para um regime de capitalização ainda não eram as mudanças demográficas, mas apenas o comportamento dos indivíduos dentro do sistema de repartição. Segundo Feldstein (1975), ao reduzir-se a poupança agregada, reduzir-se-ia também o volume de fundos destinados ao investimento e por consequência aumentaria a taxa de juros básica, reduzindo a capacidade 
de produção da economia. Dessa maneira, regimes de capitalização seriam benéficos ao desenvolvimento econômico.

Surge, de tempos em tempos, em todo país com grandes mudanças demográficas uma grande pergunta: Como adaptar a previdência social? Essas mudanças são causadas pela redução da taxa de fecundidade e mortalidade, influenciadas pelo avanço tecnológico e da medicina como métodos contraceptivos e tratamentos médicos.

Giambiagi (2019) utiliza como contexto o estudo do Banco Mundial de 1994 que define três pilares para a previdência social: todos indivíduos a partir de uma certa idade receberiam um benefício mínimo independente de contribuições prévias, existência de um teto baixo para quem estivesse no mercado formal e por fim um regime de capitalização com contribuição definida em contas individuais.

Com o aumento da expectativa de vida, torna-se necessário um aumento das contribuições para ser possível garantir o mesmo padrão de vida das gerações passadas aos aposentados (GIAMBIAGI, 2019). Esse movimento tem um limite, o aumento de impostos (já bastante elevados no Brasil) reduz o poder de consumo da população, desacelerando a economia. Surge assim a opção do regime de capitalização: cada um seria responsável por sua própria aposentadoria, sem a necessidade de sustentar o crescente número de idosos. Esse sistema seria menos sujeito às mudanças demográficas que regimes de repartição (HEMMING, 1999).

A maneira com que os países do mundo vêm enfrentando mudanças demográficas variam por meio de duas formas: mantendo o regime de repartição e elevando idade de aposentadoria mínima ou anos exigidos para se aposentar, ou passando para o regime de capitalização iniciado pelo Chile em 1981 e seguido por outros 40 países.

A base do sistema previdenciário de repartição é a população economicamente ativa sustentando os aposentados, ou seja, contribuinte e beneficiário. A nossa demografia mudou com o tempo passando de uma relação contribuinte/beneficiário de 2,5 em 1991 para 1,6 em 1997. (NAJBERG, 1999) 
Segundo Sachs (1998), uma desvantagem do sistema de repartição seria o comportamento dos indivíduos diante da desvinculação entre benefícios e contribuições, como um tributo e um direito independentes. $\mathrm{O}$ problema nisso reside em sobrecarregar as alíquotas ao ponto de um crescimento excessivo do mercado informal, podendo inclusive agravar o déficit.

O brasileiro paga hoje de $8 \%$ a $11 \%$ na alíquota do INSS. Nas contas de Giambiagi (2019), um sistema de capitalização no Brasil com rendimento de $5 \%$ ao ano seria capaz de garantir uma renda complementar idêntica ao último salário do indivíduo supondo que ele trabalhe dos 20 até os 60 e contribua $11,67 \%$ na alíquota. Em outro cenário, com um rendimento de $3 \%$ ao ano e um período de trabalho de 20 até os 50 anos, essa renda complementar idêntica ao último salário só poderia ser mantida se a alíquota fosse elevada para 45,16\%. Em ambos os cálculos o indivíduo receberia a renda complementar até os 85 anos e as empresas contribuiriam com $20 \%$.

Giambiagi (2019) considera a manutenção de um sistema que proveja uma renda complementar idêntica ao último salário extremamente difícil. Um sistema de capitalização não deve assumir riscos em sua estratégia de rentabilidade e deve priorizar baixos riscos em detrimento de rentabilidade. Além disso, deve-se analisar as possibilidades de alteração da alíquota das empresas e também do uso do FGTS, que poderia ser integrado na capitalização. Os fatores listados estão no cerne da discussão da previdência por capitalização dentro da realidade brasileira.

\subsection{A previdência social em outros países}

Segundo Nery (2017), entre 1995 e 2017 pelo menos 55 países no mundo elevaram a idade legal de aposentadoria, 60 países reduziram os benefícios e 32 países adotaram alguma forma de capitalização em seus regimes previdenciários.

Usando como referência as experiências na Grécia, Chile, Argentina e Polônia, podem-se observar as diferentes estratégias 
adotadas para lidar com as mudanças demográficas em seus territórios. Nery (2017) fala sobre a Grécia e Najberg (1999) detalha o esforço dos três últimos.

Talvez uma das mais famosas experiências internacionais seja a da Grécia. A República Helênica é considerada o berço da civilização ocidental e influenciou o mundo inteiro com suas conquistas na Antiguidade Clássica, mas em 2009 não foram seus louros que chamaram a atenção do mundo. Primeiro, é importante notar que a crise fiscal grega não teve origem apenas com a crise previdenciária, mas no início de sua crise já possuía regras previdenciárias mais rígidas que as brasileiras, uma dívida pública menos arriscada segundo o mercado e uma relação de despesa previdenciária com PIB e razão de dependência semelhantes à brasileira (NERY, 2017). A crise grega se deu no momento em que a razão de dependência (pessoas em idade ativa por idoso) era de 3,28. Para comparação, hoje temos no Brasil 7,09, com uma previsão de chegarmos ao mesmo nível grego até 2042.

O país que crescia rapidamente elevava seus gastos públicos mais rápido ainda. Desde 1971 sem conseguir fechar o ano com superávit primário, a Grécia gastava $17,4 \%$ do PIB com a previdência ou $31,5 \%$ do seu total de despesas. Em 2009 a crise fiscal estourou e o país ficou devastado: a dívida chegou a $188,7 \%$ do PIB, a renda média do indivíduo grego caindo para quase a metade e a taxa de desemprego entre jovens chegando a $60 \%$.

Apenas em 2010 com uma série de medidas de austeridade fiscal (como sempre impopulares, desta vez causando protestos violentos e algumas mortes) a Grécia conseguiu recuperar algum fôlego. Depois de ter uma queda do PIB histórica em 2011 de 9,1\%, o país só voltou a ter um crescimento em 2017, com 1,4\%. A Grécia manteve o regime de repartição, mas precisou alterar rigorosamente alguns pontos: Em 2011, a idade mínima foi igualada para homens, mulheres e trabalhadores dos setores públicos e privados em 65 anos. Em 2012, a idade mínima foi aumentada para 67 anos e decidido que a partir de 2020 o aumento estará diretamente vinculado ao aumento de expectativa de vida do país. 
Em 2016, o país reduziu os benefícios para alguns aposentados em $50 \%$, trazendo muitos deles para abaixo da linha da pobreza definida pela U.E. Essas medidas, juntas a empréstimos de aliados europeus e outros pacotes de austeridade, foram cruciais para a recuperação econômica grega.

No Chile, a alíquota é de $13 \%$ do salário do contribuinte, sendo $10 \%$ para a sua aposentadoria e $3 \%$ para cobrir taxas de administração e um seguro-desemprego. $O$ estado, nesse caso, atua apenas como agente regulador. Apesar de cada indivíduo montar a sua própria aposentadoria, o Estado estabeleceu um mínimo para todos aqueles que trabalharem ao menos 20 anos, para assim até os contribuintes menos afortunados conseguirem uma aposentadoria considerada digna. Nesse caso, os recursos são originários de outras fontes. A implantação não enfrentou grande dificuldade, por ocorrer no período ditatorial de Pinochet e reduzir as alíquotas de $19,6 \%$ para $10 \%$, o empregador ficou isento. A transição não foi tão fácil e gerou grande ônus fiscal, mas a longo prazo tornou o regime de previdência sustentável.

$\mathrm{Na}$ Argentina, o novo sistema entrou em vigor em 1994 e funciona à base de dois pilares: um benefício básico pré-definido pago a todo trabalhador com pelo menos 30 anos de contribuição, como no sistema de repartição. Além disso, um benefício complementar que pode ser também nos moldes de repartição ou um programa de contribuição definida pelas contas individuais capitalizadas. $O$ impacto da transição foi mais suave, pois ao contrário do Chile, o reconhecimento das contribuições do antigo sistema é feito através de pagamentos mensais e não de um estoque. Uma diferença também reside no fato da alíquota de contribuição permanecer inalterada em $11 \%$ para contribuintes e $16 \%$ para empregadores.

Na Polônia, existe a chamada "capitalização escritural" que funciona também em dois pilares: uma contribuição definida controlada por uma agência estatal e uma outra contribuição definida administrada por companhias privadas. A alíquota de contribuição é alta, 21\% para o trabalhador e $24 \%$ para o empregador. $62,5 \%$ do recolhido vai para a 
agência estatal e 37,5\% para as agências privadas. Essas agências privadas fazem o papel de capitalização, sendo a responsabilidade de escolher o fundo desejado do próprio contribuinte. Apesar de o primeiro pilar ser do caráter de repartição, suas regras estão vinculadas àquele de capitalização no sentido de o benefício ser calculado pela divisão entre 0 "capital virtual" acumulado e a expectativa média de sobrevida. A transição foi mais tranquila devido ao maior papel do estado no sistema.

\subsection{A generosidade paramétrica}

Ao observar as regras da previdência brasileira em comparação às de outros países, percebe-se uma disparidade (GIAMBIAGI, 2004). Enquanto nossa idade média de aposentadoria é de 55 anos, diversos países com expectativa de vida semelhante à nossa (75 anos) possuem uma população se aposentando mais tardiamente, como é o caso do México aos 65 anos, Argentina aos 65 anos, Estônia aos 63, Lituânia aos 63. China aos 60 e África do Sul aos 60. O Brasil tem a menor idade média de aposentadoria do BRICS, mesmo tendo uma expectativa de vida maior que Rússia, Índia e África do Sul.

Para o PIB que possuímos ( $R \$ 6,8$ trilhões em 2018), o Brasil é extremamente generoso dentro do seu sistema previdenciário. Proporcionalmente, o país gasta o mesmo que países com $20 \%$ da população formada por idosos, mesmo tendo apenas $6,5 \%$.

Giambiagi (2019) ainda aponta alguns pontos relevantes na nossa concessão de aposentadorias: população rural se aposentando cinco anos aquém da idade exigida pelos trabalhadores urbanos; a aposentadoria por tempo de contribuição (independentemente da idade), algo raramente visto fora do Brasil; a aposentadoria prévia das mulheres em relação aos homens, sendo cinco anos tanto para a idade mínima como para o tempo de contribuição, fator que está caindo em desuso pelo resto do mundo.

Por trás desses pontos, há de se destacar as justificativas para essas diferenças e seus contrapontos. O trabalhador rural, por exemplo, possui uma expectativa de vida menor que o urbano, além de ter sua 
força deteriorada com mais intensidade devido à característica natural de seu ofício. As mulheres muitas vezes fazem jornada dupla de trabalho, pois além de trabalharem são as responsáveis pela casa, gerando um desgaste maior (IBGE, 2012), embora o homem contribua mais em trabalhos remunerados.

A Figura 3 com dados do Banco Mundial revela o quão fora da curva o Brasil se encontra no quesito de gastos com a previdência em relação com o PIB em paralelo a \% de população idosa (65 anos de idade ou mais). É de se esperar que países com uma população mais idosa reservassem uma \% maior de seus gastos a previdência, mas o Brasil é o único país que possui menos de $15 \%$ da sua população total composta por idosos e mais de $10 \%$ de gasto previdenciário em relação ao PIB, sendo classificado em um quadrante exclusivo (Giambiagi, 2019).

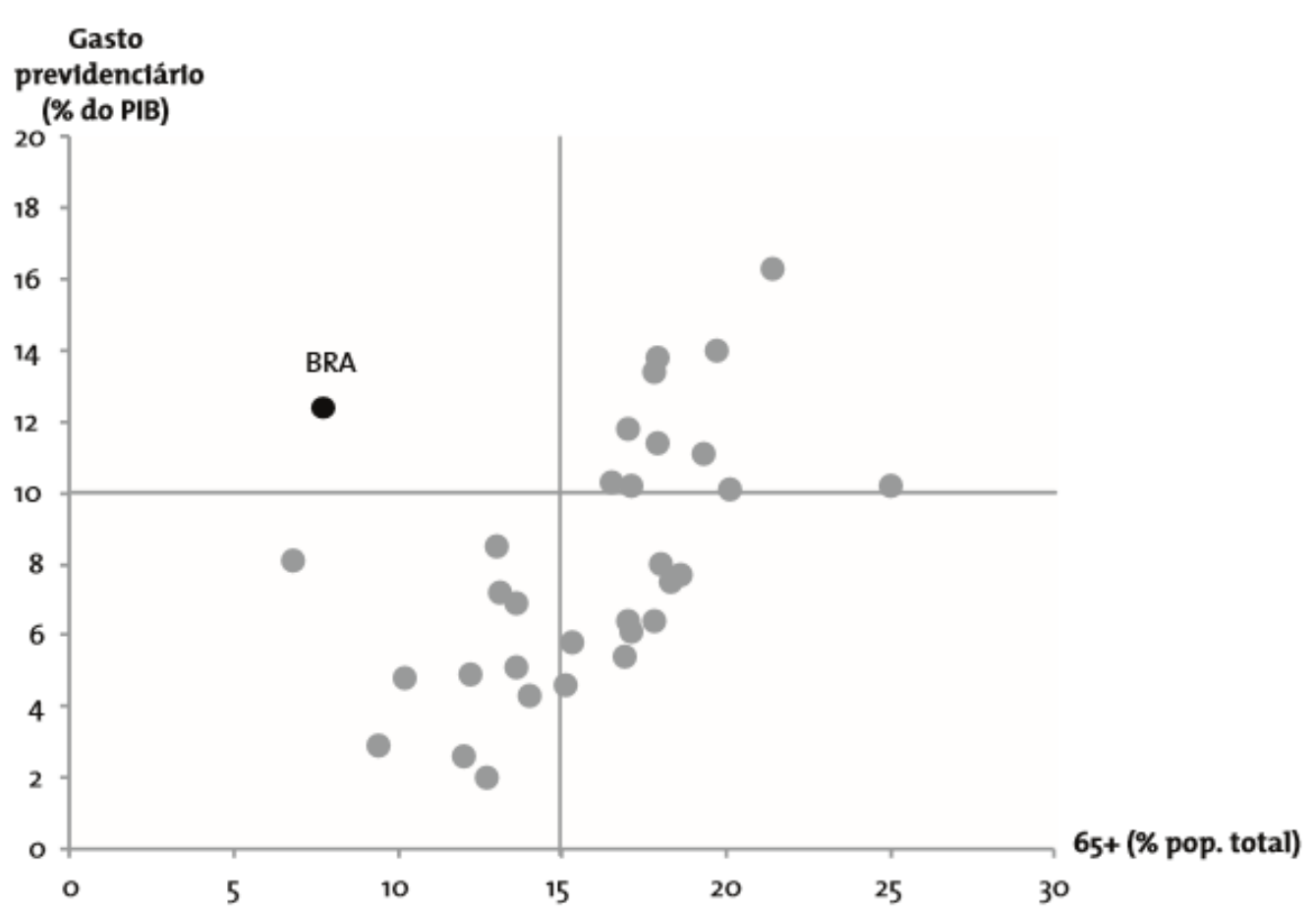

Figura 3: Gasto previdenciário x População idosa

Fonte: Banco Mundial, Giambiagi (2019) 


\section{Metodologia}

Na metodologia, introduz-se todo o processo científico envolvido no planejamento, execução e comunicação dos resultados da pesquisa. $O$ objetivo deste capítulo é contemplar o delineamento da pesquisa, as técnicas de coleta e análise de dados e limitações do estudo. A metodologia pode ser entendida como o método e conjunto de processos empregados na investigação e na demonstração da verdade (Cervo et al., 2007).

O delineamento da pesquisa trata do planejamento da pesquisa, molda seu formato e perspectiva de análise. Segundo Vergara (2007), os tipos de estudos dividem-se em exploratório, descritivo e explicativo, dependendo da sua finalidade.

Para este trabalho, usou-se o tipo de pesquisa descritivo. Desse modo, busca-se relacionar características e variáveis com o objeto de estudo, seu objetivo é proporcionar uma nova visão a uma realidade já observada.

O trabalho em questão se fundamenta através da análise de dados secundários, aqueles que estão disponíveis para consulta. Esses dados serão colhidos de artigos acadêmicos como de Feldstein (1974), Giambiagi (2004), Giambiagi (2019), Nascimento (2015) e instituições governamentais e de pesquisa como IBGE, Banco Mundial e OCDE. Os mesmos serão utilizados para analisar as transformações demográficas e contas públicas do Brasil, assim como a de outros países para comparação.

Ao fim, a apresentação de resultados buscará explicitar as vantagens e desvantagens de se adotar uma reforma previdenciária como nos moldes colocados em prática por outros países e como a proposta do atual governo do Brasil. 


\section{Análise dos Dados}

Dado que o objetivo desse trabalho é oferecer dados, argumentos e informação acerca da previdência social brasileira e da reforma previdenciária prevista para 2019 a fim de saber se o Brasil tem a capacidade de sair da crise fiscal, a metodologia descritiva foi utilizada para relacionar características e variáveis já observadas com o objeto de estudo.

De início, é necessário abordar a proposta enviada pelo governo Bolsonaro ao Congresso após suas alterações. A proposta do atual governo Bolsonaro tem a intenção de mudar diversos pontos do regime atual:

a) Fim da aposentadoria por tempo de contribuição.

b) Idade mínima de 65 anos para homem e 62 anos para mulher.

c) Aumento do tempo mínimo de contribuição com o INSS de 15 para 20 anos para homens. Permanece em 15 para mulheres.

d) Aposentado só recebe $100 \%$ do benefício se contribuir com o INSS por 40 anos.

e) Três regras de transição: por pontos, idade mínima e com um pedágio de 50\% em relação ao tempo que falta. (Medida adotada com o objetivo de tornar a transição mais suave, permitindo por mais alguns anos a aposentadoria antes da idade mínima até chegarmos a uma estabilidade)

f) Quem ganha mais pagará mais, passando de uma alíquota de $11 \%$ para 11,68\%. Quem ganha menos pagará menos, passando de uma alíquota de $8 \%$ para $7,5 \%$.

g) Pensão de morte para viúvos órfãos cairá de $100 \%$ para $60 \%$ com um dependente.

h) Abono do PIS será pago só para aqueles que recebem até 1,4 salário mínimo, ao invés de 2 como é hoje.

O governo ainda não definiu os pontos exatos de uma possível transição para o regime de capitalização e aguarda a aprovação da reforma nos demais poderes para iniciar os processos. Além disso, a 
proposta ainda pode passar por mudanças na câmara e ter pontos alterados. Paulo Guedes define a reforma da previdência como "a parede que segura o teto fiscal". A economia prevista, segundo a Comissão Especial na Câmara, é de $\mathrm{R} \$ 1,071$ trilhão em dez anos.

Ao comparar os pontos da reforma proposta com os artigos levantados como o de Giambiagi (2004) e Giambiagi (2019), os resultados encontrados convergem com os autores analisados em pontos como a generosidade paramétrica do Brasil em relação a outros países. Observase na Figura 4 uma comparação entre o Brasil, países do BRICS e a média da OCDE no quesito diferença entre expectativa de vida ao nascer e idade média de aposentadoria para o indivíduo que começou a trabalhar com 20 anos. Essa disparidade corrobora com os estudos de Giambiagi (2004).

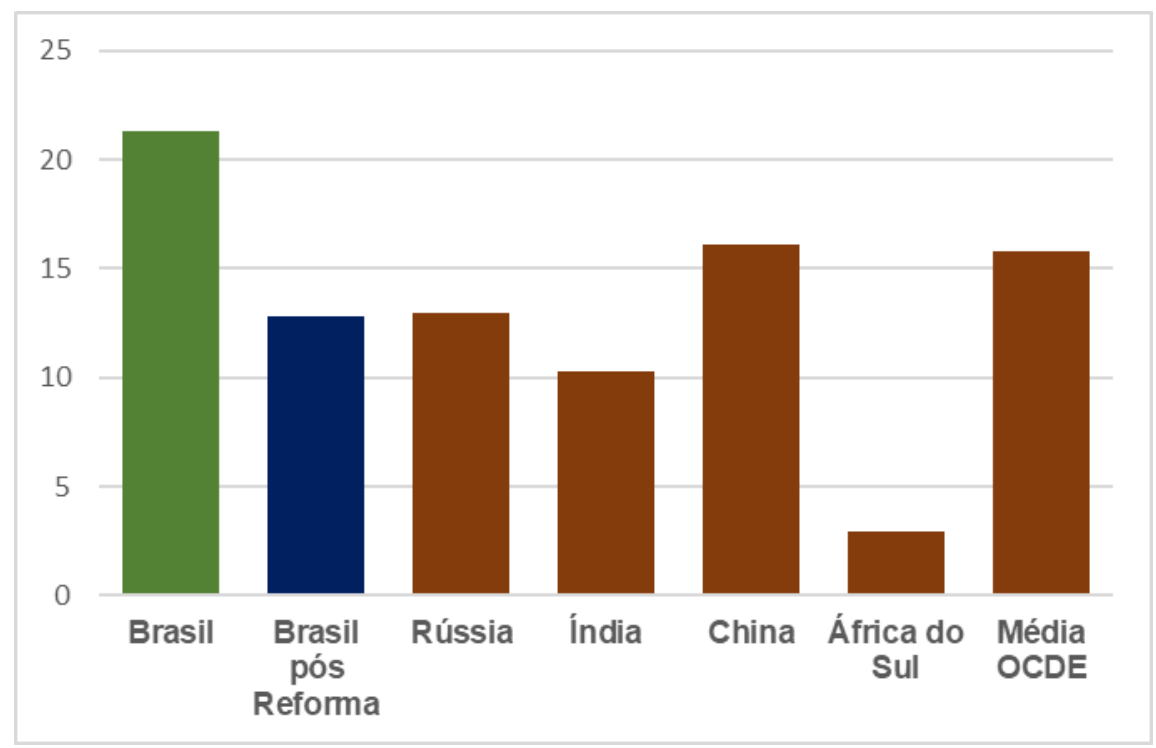

Figura 4: Diferença entre expectativa de vida e idade média de aposentadoria (em anos)

\section{Fonte: Elaborada pelo autor com base em dados da OCDE}

$\mathrm{Na}$ proposta, o aumento da idade mínima de aposentadoria seguiria os passos de outros 55 países no mundo nas últimas duas décadas. Nesse mesmo tempo, a redução de alguns benefícios sociais seguiria o mesmo caminho de outros 60 países e uma possível adoção, em qualquer nível, de um sistema de capitalização seguiria os passos de outros 32 países pelo mundo. De acordo com os levantamentos de Nery 
(2017), estaríamos nos adequando às mudanças internacionais com um regime de austeridade e responsabilidade fiscal. O fim da aposentadoria por tempo de contribuição nos tiraria de um grupo bastante restrito composto por apenas 12 países: Brasil, Equador, Síria, Irã, Arábia Saudita, lêmen, Argélia, Egito, Bahrein, Hungria e Sérvia.

As idades mínimas escolhidas nos colocariam junto a outros países semelhantes ao nosso. No BRICS, por exemplo, a idade média de aposentadoria para pessoas que começaram a trabalhar aos 20 anos é de 59, enquanto no Brasil é de 55. Além disso, esses países ainda possuem uma expectativa de vida menor que o Brasil.

Ao compararmos a idade mínima de aposentadoria proposta com outros países com expectativa de vida semelhante à nossa (76,3 anos), observamos que os 65 e 62 anos propostos estaria de acordo com países como México aos 65 anos, Argentina aos 65 anos, Estônia aos 63 anos, Lituânia aos 63 anos, China aos 60 anos e África do Sul aos 60 .

A Expectativa de Sobrevida revela quantos anos o indivíduo viverá em média após uma certa idade (no caso, aos 65 anos). Ao comparar a Expectativa de Sobrevida aos 65 anos brasileira e de outros com a proposta analisada (Figura 6), observa-se que o aumento proposto é mais que o suficiente para equilibrar o Brasil com o restante do mundo na demografia atual e durante muitos anos.

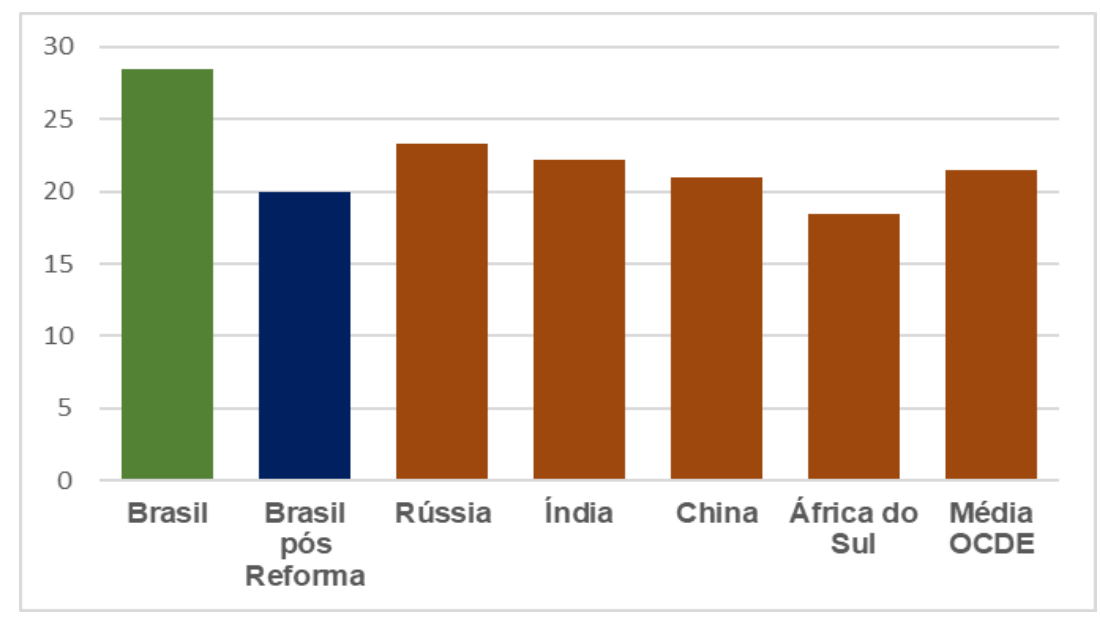

Figura 5: Diferença entre expectativa de sobrevida aos 65 anos e idade média de aposentadoria (em anos)

Fonte: Elaborada pelo autor com base em dados da OCDE 
Observa-se que o Brasil possui pontos em comum com a Grécia em sua recente crise econômica que assustou toda a união europeia e o mundo, como por exemplo os altos gastos previdenciários em relação ao PIB. A razão de dependência está longe do controle do governo e continuará a cair com o aumento de \% de pessoas em idade ativa em comparação a \% de idosos. Porém, com a reforma apresentada o Brasil reduziria drasticamente seu gasto previdenciário, saindo do quadrante solitário destacado por Giambiagi (2019) dos países com mais de 10\% de gasto previdenciário em relação ao PIB e menos de $15 \%$ de população idosa. Essa mudança aliviaria os gastos públicos totais $(R \$ 3,46$ trilhões em 2018) sobrando mais dinheiro para o investimento em saúde e educação, como observado na Figura 5, e reverteria o contínuo aumento que estamos tendo na \% de gastos previdenciários dentro dos gastos totais.

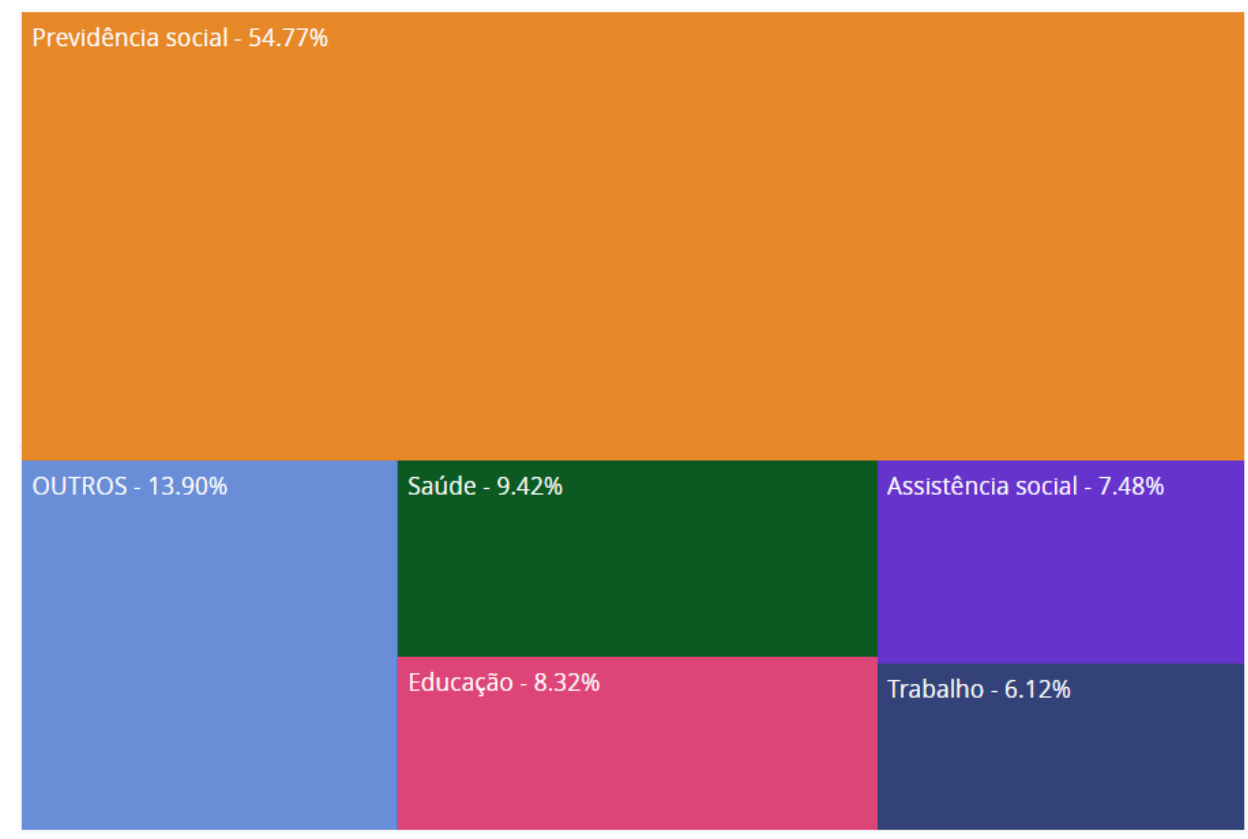

Figura 6: Despesa pública federal em 2018 por área de atuação Fonte: Portal da Transparência Governamental (2018)

Além disso, o Brasil caminharia para ter novamente superávit primário (ausente desde 2014) e não mais teria que lidar com um rombo de centenas de bilhões na previdência. 
Observa-se que o Brasil quando comparado ao BRICS e outros países possui não apenas uma idade média de aposentadoria para quem começa a trabalhar aos 20 anos (IMA(20)) menor que a média, mas uma Expectativa de Vida (EV) maior, assim como uma Expectativa de Sobrevida aos 65 anos (ES(65)) também acima da média. O Brasil também se difere por ser o único sem idade mínima de aposentadoria, tanto para homem $(\operatorname{IAM}(h))$ como para mulher $(\operatorname{IAM}(m))$.

\begin{tabular}{lccccc}
\hline País & IMA(20) & IAM(h) & IAM $(\mathrm{m})$ & EV & ES(65) \\
\hline Brasil & 55 & - & - & 76,3 & 83,7 \\
Rússia & 57,5 & 65 & 60 & 71,8 & 80,6 \\
Índia & 58 & 60 & 60 & 68,4 & 81,0 \\
China & 60 & 60 & 55 & 76 & 81,3 \\
África do Sul & 60 & 60 & 60 & 57,5 & 77,5 \\
Chile & 62,5 & 65 & 60 & 79,9 & 84,45 \\
México & 65 & 65 & 65 & 75,4 & 82,75 \\
E.U.A. & 61,5 & 66 & 66 & 78,6 & 84,3 \\
Reino Unido & 64 & 65 & 63 & 81,2 & 84,95 \\
França & 62 & 65 & 65 & 82,4 & 86,45 \\
\hline Média & 60,6 & 63,4 & 61,6 & 74,8 & 82,7 \\
\hline
\end{tabular}

Tabela 1: Comparativo Demográfico e Previdenciário

Fonte: Elaborada pelo autor com base em dados da OCDE 


\section{Conclusão}

Este trabalho teve o intuito de analisar o sistema previdenciário brasileiro em contraste com o de outros países e identificar a capacidade do Brasil de superar a atual crise previdenciária causada pelas mudanças demográficas somadas à generosidade paramétrica do nosso regime em conjunto a outras crises econômicas pelas quais passamos que unidas nos trouxeram à uma situação alarmante. $O$ trabalho buscou utilizar fontes diversas que demonstrassem descritivamente as sucessivas reformas previdenciárias ao redor do mundo e diferentes demografias a fim de relacioná-las à realidade brasileira e à proposta do governo.

Os resultados encontrados demonstram um alinhamento da proposta do governo brasileiro com os movimentos do restante do mundo, ao adequar as regras previdenciárias às mudanças demográficas comuns em todo o mundo nos últimos 40 anos o Brasil se prepararia para incentivar sua economia e poupar os esforços públicos em outras áreas como saúde, educação, segurança e outros investimentos.

A previdência social é uma ferramenta criada com a intenção de ajudar os indivíduos em suas últimas fases de vida, principalmente aqueles que teriam mais dificuldade em poupar para a vida idosa onde não se tem mais a capacidade de trabalhar. $A$ ideia por trás do sistema só pode ser cumprida se ela estiver alinhada com as realidades econômicas e demográficas do país, respeitando as capacidades e encarando a realidade. A recusa em aceitar os fatos pode levar o país a um abismo onde o inverso será realidade: o Estado não teria mais capacidade de bancar as aposentadorias e não conseguiria mais investir em outras áreas públicas, causando um mal geral à população por anos, desperdiçando gerações e atrasando a sociedade em geral. 


\section{Referências}

CERVO, Amado L.; BERVIAN, Pedro A.; da SILVA, Roberto. Metodologia científica. 6. ed. São Paulo: Pearson Prentice Hall, 2007

DESPESAS PÚBLICAS, 2019. Disponível em: $<$ http://www.portaldatransparencia.gov.br/despesas?ano=2018>. Acesso em: 16 de jun. de 2019.

Estatísticas Sociais. Em 2017, expectativa de vida era de 76 anos. IBGE, dez. 2018. Disponível em: <https://agenciadenoticias.ibge.gov.br/agencia-sala-de-imprensa/2013agencia-de-noticias/releases/23200-em-2017-expectativa-de-vida-era-de76-anos> Acesso em: 13 mai. 2019.

FELDSTEIN, M. Social security, induced retirement, and aggregate capital accumulation. The Journal of Political Economy, v. 82, n. 5, p. 905-926, 1974. Disponível em: . Acesso em: 2 mai. 2019.

GIAMBIAGI, Fabio; AFONSO, Luis Eduardo. Alíquota previdenciária em um regime de capitalização: uma contribuição ao debate. Rio de Janeiro : Banco Nacional de Desenvolvimento Econômico e Social, 2019.

GIAMBIAGI, Fabio; MENDONÇA, Joao Luis; ARDEO, Vagner. Diagnóstico da Previdência Social no Brasil: O Que Foi Feito e o Que Falta Reformar? Brasília : Instituto de Pesquisa Econômica Aplicada, 2004.

HEMMING, R. Should public pensions be funded? International Social Security Review, v. 52, n. 2, p. 3-29, 1999. Disponível em: . Acesso em: 22 mai. 2019. 
MIRANDA, Gabriela; MENDES, Antonio; SILVA, Ana Lucia. 0 envelhecimento populacional brasileiro: desafios e consequências sociais atuais e futuras Rev. bras. geriatr. gerontol. vol.19 no.3 Rio de Janeiro mai./jun. 2016.

MUNNELL, A. H. The impact of social security on personal savings. National Tax Journal, v. 27, n. 4, p. 553-567, 1974. Disponível em: . Acesso em: 22 mai. 2019.

Mulheres se dedicam quase o o dobro do tempo dos homens em tarefas domésticas, 2012. Disponível em: $<$ https://agenciadenoticias.ibge.gov.br/agencia-noticias/2012-agencia-denoticias/noticias/24267-mulheres-dedicam-quase-o-dobro-do-tempo-doshomens-em-tarefas-domesticas>. Acesso em: 02 de jun. de 2019.

NAJBERG, Sheila; IKEDA, Marcelo. Previdência no Brasil: desafios e limites. In: GIAMBIAGI, Fabio; MOREIRA, Maurício Mesquita (Org); ALÉM, Ana Cláudia et al. A economia brasileira nos anos 90. 1. ed. Rio de Janeiro : Banco Nacional de Desenvolvimento Econômico e Social, 1999. p. 261-290.

NASCIMENTO, Cristine Emily. Aumento na expectativa de vida e a incidência na previdência social. In: Âmbito Jurídico, Rio Grande, XVIII, n. 133, fev. 2015.

NERY, Pedro. GRÉCIA E BRASIL: um exercício de comparação de regimes previdenciários Brasília : Instituto de Pesquisa Econômica Aplicada, 2017.

OECD: Life Expectancy at 65, 2019. Disponível em: $<$ https://data.oecd.org/healthstat/life-expectancy-at-65.htm\#indicatorchart>. Acesso em: 16 de jun. de 2019. 
SACHS, J. (1998). Notes on the transition to a privatized pension system. Apresentado em The Global Social Security Crisis An EDI-HIID Workshop. July, mimeo.

THE WORLD BANK DATA. WORLD BANK, 2019. Disponível em: $<$ https://data.worldbank.org/country/brazil?locale=pt>. Acesso em: $31 \mathrm{de}$ mai. de 2019.

VERGARA, Sylvia Constant. Projetos e Relatórios de Pesquisa em Administração. 9. ed. São Paulo: Atlas, 2007 